\title{
The Effect of SSC Model on Environmental Cognition
}

\author{
Vikas Minchekar* and Rutuja M Sabane \\ Department of Clinical Psychology, Smt. Kasturbai Walchand College, India
}

Submission: March 23, 2017; Published: March 30, 2017

*Corresponding author: Vikas Minchekar, Associate Professor in Psychology, Dept. of Clinical Psychology, Smt. Kasturbai Walchand College, Sangli, Maharashtra, India, Email: vikasminchekar@yahoo.com

\begin{abstract}
Environmental cognition is a multidisciplinary concept in nature. It is an emerging concept of cognitive and social psychology. It indicates that how people hold the perceptions and attitudes towards their own ecological surroundings and how these perceptions, cognitions, and attitudes develop over time. Moreover, this concept refers to the fact that how individual's structure, their thinking about environmental issues, how are these cognitions acquired, and how do they influence behaviors regarding nature? Environmental awareness is a burning issue of the 21st century. If we still not became aware of the challenges of environments; the day is not far away from where we ruin our planet by our own hands. Environmental awareness is a very important issue to promote sustainable development and encourages conservation of natural resources. Environmental awareness essentially serves as an educational tool, helping people to understand the importance of preserving natural resources. Moreover, it helps people to understand the consequences of anti-nature activities.
\end{abstract}

Keeping this reality makes researcher anxious to do something as an obligation regarding our own planet. The researcher has developed an own model and it employed on 85 college students. The SSC model refers Story, Speech, and Counseling. The present research has undergone through pre and posttest repeated measure design. At the first phase, the 85 college students ranged in an age of 18 to 25 years were selected by convenience accidental sampling method. They were administered scale as follows: 1 EACS-Ecological Attitude and Cognitive Science, 2. EPAS- Environmental Pollution Attitude Scale, 3. EKT- Environmental Knowledge Test, 4. EES- Environmental Ethics Scale, 5. APAS- Air Pollution Attitude Scale, 6. EAS- Environmental Attitude Scale. After a month they were gathered for an interactive session in which researcher have delivered an environmental awareness lecture by using little stories. Moreover, researcher provides a personal guidance and counseling to the participated students. In the post test condition, participated students again administered the previous scales. The obtained data was analyzed through ' $t$ ' test. The results revealed a significant difference in pre and posttest conditions. The results are discussed in the full paper [1].

Keywords: SSC Model; Environmental Cognition

\section{Introduction}

Environmental Psychology is an interdisciplinary field focused on the interplay between humans and their surroundings. The field defines the term environment broadly, encompassing natural environments, social settings, built environments, learning environments and informational environments. Since its conception, the field has been committed to the development of a discipline that is both value oriented and problem oriented, prioritizing research aimed at solving complex environmental problems in the pursuit of individual well-being within a larger society. When solving problems involving human-environment interactions, whether local or global, one must have a model of human nature that predicts the environmental conditions under which human will behave. This model can design, manage and restore environments that enhance reasonable behavior, predict the likely outcomes when these conditions are not met, and diagnose the problematic situation. The field develops such a model of human nature while retaining a broad and inherently multidisciplinary focus. It explores such dissimilar issues as common property resource management, way finding in complex settings, the effect of environmental stress on human performance, and the characteristic of restorative environments, human information processing and the promotion of durable conservation behavior.

In this project, by carrying out pretest and then posttest after application of SSC (i.e. Story, Speech, and Counseling) model, we measured the change quantitatively. The measurement of basic environmental knowledge, Attitude towards the environment, i.e. various environmental problems, the effect of pollution on 
the efficiency, ecological cognition, and environmental ethics has been done in the present study. Environmental cognition includes basic knowledge about the environment, interest in solving environmental issues, etc. In the treatment condition, based on SSC model, the researcher tried out to find out the reason and attitude behind answering the questions in the pretest also. Researcher discussed how we can make ourselves environmental-friendly and emphasize the importance of active participation of each one of us for the betterment of the environment and ultimately of our life. The effect of SSC model was checked with the help of posttests.

'Environmental Science' though made a compulsory subject in certain academic years; still, most of the students don't have the favorable attitude towards environment protection. This is researcher's small effort to at least give a new perspective to students about the environment [2,3].

\section{Objectives}

a. To check the usefulness of SSC model to increase the environmental Knowledge.

b. To study the effectiveness of SSC model to modify ecological attitude and cognition.

c. To find out the impact of SSC model on youth in changing their attitude towards environmental pollution. (Especially air pollution is taken under the study).

d. To explore the usefulness of SSC model in developing the environmental ethics in the youth.

\section{Hypotheses}

a. The SSC model will make a significant increase in environmental knowledge among youth.

b. The SSC model will be proved effective to modify ecological attitude and cognition.

c. The SSC model will have a strong impact on youth for changing their attitude towards environmental pollution.

d. The SSC model will be useful to develop environmental ethics.

\section{Method}

\section{Sample}

The sample for this study was drawn from various departments of the college, private tuition comprising students from various faculties like arts, pure science, biotechnology, computer science, computer networking, and commerce. Altogether 85 students participated in a study out of which 50 are females and 35 are males. The age group taken for this study is between 18 to 25 years. This is because; most of them have gone through basic environmental education from their academic syllabus and them as being the youth will lead to the positive change.

\section{Measures}

The following psychological tests are carried out to determine the environmental cognition of students.

EKT- Environmental Knowledge Test by Dr. Seema Dhavan.

In this test, there are 80 questions of following dimensions (Table 1).

Table 1: Dimensions of 80 questions.

\begin{tabular}{|c|c|c|}
\hline Sr. No. & Dimensions & No. of statements \\
\hline 1 & Forest including trees & 14 \\
\hline 2 & Pollution (air, water, noise, and soil) & 20 \\
\hline 3 & Wildlife and animals & 14 \\
\hline 4 & Energy Conservation & 5 \\
\hline 5 & Environmental and related problems & 21 \\
\hline 6 & Teaching method of EE & 3 \\
\hline 7 & Population & 3 \\
\hline
\end{tabular}

EACS- Ecological Attitude and Cognitive Scale by Dr. Rajamanickam.

This test includes following scales:

a) The Oral Obligation Scale: This sub-class is intended to assess an individual's oral commitment to deal with ecological problems. The possible higher score is 10 and the low score is zero. The high score indicates afavorable attitude towards the ecological problems and the low score indicates anunfavorable attitude towards the problem.

b) The Real Obligation Scale: The real obligation scale is to test one's practical approach towards the ecological problems. Whether the person has done really anything in the past to solve the problems and also whether he/she is doing anything at present is tested by this scale. This scale also reveals the person's mode of approach to solving the existing ecological problems. There are ten statements referring to the actual commitment of the person to solving the environmental problems, of which five are positive statements and five negative statements.

c) The Emotional Obligation Scale: This scale is used for the purpose of finding out the degree of feeling the individual expresses when he faces with some ecological problems and issues. There are ten statements referring to the feeling aspect towards the environmental issues.

d) The Cognitive Scale: The cognitive scale is intended to assess a person's knowledge about the ecological issues and problems. It is assumed that if a person is really interested in these problems he may know more about solving the problems.

EPAS- Environmental Pollution Attitude Scale by Dr. M. Rajamanickam. 
This test consists of 30 statements. All the 30 statements are referring to some aspect of environmental pollution. The 15 positive statements express that there is environmental pollution and it is the matter of concern while the 15 negative statements express that there is no environmental pollution and some people make exaggeration about this. Under each statement, five responses such as strongly agree, agree unable to decide, disagree and strongly disagree are provided.

APAS- Air Pollution Attitude Scale by Dr. M. Rajamanickam.

The objectives of this test are:

a. to test whether a person is aware of the air pollution in the atmosphere,

b. to test whether the person is having any idea about the consequences of air pollution,

c. to test whether the person is really interested in controlling the air pollution,

d. To see whether the person has taken any steps individually or jointly to control the air pollution.

There are total 30 statements. Each one of it has five responses from strongly agree to strongly disagree.

EAS- Environmental Attitude Scale by Dr. Haseen Taj.

Area-wise \& Type-wise Distribution of items in this Test (Table 2):

Table 2: Area wise and type wise distribution of items.

\begin{tabular}{|c|c|c|c|c|}
\hline Sr. No. & Areas & $\begin{array}{l}\text { Nature of } \\
\text { Item }\end{array}$ & $\begin{array}{l}\text { Total No. of } \\
\text { Items }\end{array}$ & Total \\
\hline \multirow{2}{*}{ I } & \multirow{2}{*}{ Health \& Hygiene } & Positive & 3 & \multirow{2}{*}{5} \\
\hline & & Negative & 2 & \\
\hline \multirow{2}{*}{ II } & \multirow{2}{*}{ Wild Life } & Positive & 1 & \multirow{2}{*}{6} \\
\hline & & Negative & 5 & \\
\hline \multirow{2}{*}{ III } & \multirow{2}{*}{ Forests } & Positive & - & \multirow{2}{*}{5} \\
\hline & & Negative & 5 & \\
\hline \multirow{2}{*}{ IV } & \multirow{2}{*}{ Polluters } & Positive & 14 & \multirow{2}{*}{26} \\
\hline & & Negative & 12 & \\
\hline \multirow{2}{*}{$\mathrm{V}$} & \multirow{2}{*}{$\begin{array}{l}\text { Population } \\
\text { Explosion }\end{array}$} & Positive & 2 & \multirow{2}{*}{5} \\
\hline & & Negative & 3 & \\
\hline \multirow{3}{*}{ VI } & \multirow{2}{*}{$\begin{array}{c}\text { Environmental } \\
\text { Concern }\end{array}$} & Positive & 11 & \multirow[b]{2}{*}{14} \\
\hline & & Negative & 3 & \\
\hline & \multicolumn{3}{|c|}{ Positive Items $=31+$ Negative Itmes $=30$} & 61 \\
\hline
\end{tabular}

In this test, there are four responses for each item as strongly agree, agree, disagree and strongly disagree.

\section{EES- Environmental Ethics Scale by Dr. Haseen Taj.}

EnvironmentalEthics refers to the responsibility tounderstand the environmental consequences of our consumption, and need to recognize our individual and social responsibility to conserve natural resources and protect the earth for future generations. An environment ethics is basically a human ethics based on social justice for all without discrimination of race, sex, religion, ideology, caste, region or nation. Most current environmental problems are essentially a result of people's activities and their attitude towards the socio-cultural and natural environments. The present day environment crisis demands a change in attitude, in order that initiatives can be taken to rescue the environment from destruction (Natural Environment Research Council, UK, 1989).

There are 45 statements in this test, each one of which has 3 responses as I absolutely agree, I slightly agree, I don't agree.

i. Procedure: The first Researcher has taken pre-tests in different classes, at each time only 15-25 students are taken. Without any prior notice, the tests have been solved. For solving the test, the minimum time is given for assuring the possibility of real response. Then after assessing the pre-tests, the SSC model was applied to them in a group. Who have curiosity or some doubts, they were counseled personally. And then after a period of a week, post-tests are taken in a similar way as that of the post-test.

ii. Treatment Condition: SSC Model: $S=$ Stories, $S=$ Speech, C= Counseling.

From these stories, speeches and if needed then by personal counseling, Researcher tried to emphasize the following points by observing the scores, facts observed while assessing the tests.

a. A small step for us leads to a big change.

b. It is the responsibility of each and every individual to contribute its all possible efforts to keep our earth beautiful.

c. We should not consider 'environmental science', as only the subject in which we can score more, rather we should look it as an opportunity to work differently for nature conservation.

d. It is not possible to have a scenic state of mind and the ultimate happiness beyond the physical goods by going away from nature.

\section{Results and Discussions}

Table 3 depicts the clear picture of EKT in pretest and posttest conditions. In the pretest, the mean value of EKT is 56.9762 with SD 7.44 while mean and SD for posttest condition is respectively 56.9524 and 7.47. The $r$ value and $t$ value is .031 which is not significant. It means that the SSC model does not make asignificant difference in EKT of participants. The reason could be as it is the knowledge test, $99 \%$ of the questions were based on the information. My model was aimed at changing the attitude towards environment positively. Hence, the effect was not significant. 


\section{Psychology and Behavioral Science International Journal}

Table 3: Showing the mean, SD, $r$ and $t$ value of Environmental Knowledge.

\begin{tabular}{|c|c|c|c|c|c|c|c|}
\hline \multicolumn{9}{|c|}{ Paired Samples Statistics } & S & t & Significance \\
\hline Pair 1 & & Mean & N & Std. Deviation & r & NS \\
\hline & EKT-1 & 56.9762 & 84 & 7.43482 & .552 & .031 & NS \\
\hline
\end{tabular}

Table 4: Showing the mean, SD, $r$ and $t$ value of Environmental Pollution Attitude.

\begin{tabular}{|c|c|c|c|c|c|c|c|}
\hline \multicolumn{8}{|c|}{ Paired Samples Statistics } \\
\hline & & Mean & $\mathrm{N}$ & Std. Deviation & $\mathrm{r}$ & $\mathrm{t}$ & Significance \\
\hline Pair 1 & EPAS-1 & 100.19 & 85 & 9.67138 & \multirow{2}{*}{.253} & \multirow{2}{*}{4.576} & \multirow{2}{*}{0.01} \\
\hline & EPAS-2 & 105.71 & 85 & 8.44284 & & & \\
\hline
\end{tabular}

Table 4 depicts the clear picture of Environmental Pollution Attitude in pretest and posttest conditions. In the pretest, the value of mean EPAS is 100.19 with SD9.67 while mean and SD for posttest condition is respectively 105.71 and 8.44 the $r$ value and $t$ value is 0.253 and 4.567 respectively which is significant.

Table 5: Showing the mean, SD, $r$ and $t$ value of Air Pollution Attitude.

\begin{tabular}{|c|c|c|c|c|c|c|c|}
\hline \multicolumn{8}{|c|}{ Paired Samples Statistics } \\
\hline & & Mean & $\mathrm{N}$ & Std. Deviation & $\mathrm{r}$ & $\mathrm{t}$ & Significance \\
\hline Pair 1 & APAS-1 & 111.72 & 85 & 11.05679 & \multirow{2}{*}{.143} & \multirow{2}{*}{1.598} & \multirow{2}{*}{ NS } \\
\hline & APAS-2 & 114.22 & 85 & 11.03067 & & & \\
\hline
\end{tabular}

Table 5 describes the clear picture of APAS in pretest and posttest conditions. In the pretest, the mean value of APAS is 111.72 with SD 11.06 while meaning and SD for posttest condition is respectively 114.22 and 11.03 . The $r$ value and $t$ value is .143and 1,598 , which is not significant. It means that the SSC model does not make a significant difference in APAS of participants. The reason could be the SSC model didn't satisfactorily proved it that pollution-free air is more important than a comfort obtained by using personal vehicles. Hence, the effect was not significant.
It means that the SSC model makes a significant difference in EPAS of participants. The reason is that with effective examples in theday to day life, I told them the ill effects of pollution. 99\% significance is observed in the posttest.

Table 6: Showing the mean, SD, $r$ and $t$ value of Environmental Attitude and Cognition.

\begin{tabular}{|c|c|c|c|c|c|c|c|}
\hline \multicolumn{8}{|c|}{ Paired Samples Statistics } \\
\hline & & Mean & $\mathrm{N}$ & Std. Deviation & $\mathrm{r}$ & $\mathrm{T}$ & Significance \\
\hline Pair 1 & EACS-1 & 27.1566 & 83 & 22.34458 & \multirow{2}{*}{.168} & \multirow{2}{*}{.478} & \multirow{2}{*}{ NS } \\
\hline & EACS-2 & 26.0000 & 83 & 4.60646 & & & \\
\hline
\end{tabular}

Table 7: Showing the mean, SD, $r$ and $t$ value of Environmental Ethics.

\begin{tabular}{|c|c|c|c|c|c|c|c|}
\hline \multicolumn{8}{|c|}{ Paired Samples Statistics } \\
\hline & & Mean & $\mathrm{N}$ & Std. Deviation & $\mathrm{r}$ & $\mathrm{t}$ & Significance \\
\hline Pair 1 & EES-1 & 110.28 & 85 & 11.96882 & \multirow{2}{*}{.01} & \multirow{2}{*}{2.587} & \multirow{2}{*}{0.05} \\
\hline & EES-2 & 114.48 & 85 & 8.98625 & & & \\
\hline
\end{tabular}


Table 7 shows the clear picture of Environmental Ethics in pretest and posttest conditions. In the pretest, the value of mean EES is 110.28 with SD11.97 while mean and SD for posttest condition is respectively 114.48 and 8.97 . The $r$ value and $t$ value is 0.01 and 2.587 respectively which is significant.

Table 8: Showing the mean, SD, $r$ and $t$ value of Environmental Attitude-a.

\begin{tabular}{|c|c|c|c|c|c|c|c|}
\hline \multicolumn{9}{|c|}{ Paired Samples Statistics } \\
\hline & & Mean & N & Std. Deviation & R & Significance \\
\hline Pair 1 & EASa-1 & 14.8353 & 85 & 2.12607 & .20 & 2.916 \\
\hline
\end{tabular}

Table 8 depicts the idea of results of Environmental attitude in pretest and posttest conditions. In the pretest, the value of mean EASa is 14.83 with SD2.13 while mean and SD for posttest condition is respectively 15.76 and 2.03.The $r$ value and t value is 0.20 and 2.916 respectively which is significant. It means that
It means that the SSC model makes a significant difference in environmental ethics of participants. The reason with counseling and storytelling, the morality is developed among the students. Hence, the SSC model worked almost $95 \%$ only in one setting.

Table 9: Showing the mean, SD, $r$ and $t$ value of EASb.

\begin{tabular}{|c|c|c|c|c|c|c|c|}
\hline \multicolumn{8}{|c|}{ Paired Samples Statistics } \\
\hline & & Mean & $\mathrm{N}$ & Std. Deviation & $\mathrm{r}$ & $\mathrm{t}$ & Significance \\
\hline Pair 1 & EASb-1 & 16.2471 & 85 & 2.24619 & \multirow{2}{*}{.035} & \multirow{2}{*}{1.987} & \multirow{2}{*}{0.05} \\
\hline & EASb-2 & 16.9294 & 85 & 2.31346 & & & \\
\hline
\end{tabular}

Table 9 depicts the clear picture of Environmental attitude in pretest and posttest conditions. In the pretest, the value of mean EASb is 16.25 with SD2.24 while mean and SD for posttest condition is respectively 16.93 and 2.31.The $r$ value and $t$ value is 0.35 and 1.987 respectively which is significant. It means that the SSC model makes a significant difference in environmental attitude of participants. The reason with counseling and storytelling, the attitude is changed positively and love for nature is developed among the students. Hence, the SSC model worked almost $95 \%$ only in one setting.

Table 10: Sshowing the mean, SD, $r$ and $t$ value of EASC.

\begin{tabular}{|c|c|c|c|c|c|c|c|}
\hline \multicolumn{8}{|c|}{ Paired Samples Statistics } \\
\hline & & Mean & $\mathrm{N}$ & Std. Deviation & $\mathrm{r}$ & $\mathrm{t}$ & Significance \\
\hline Pair 1 & EASc-1 & 14.0588 & 85 & 11.97453 & \multirow{2}{*}{.091} & \multirow{2}{*}{.265} & \multirow{2}{*}{ NS } \\
\hline & EASe-2 & 13.7059 & 85 & 1.91376 & & & \\
\hline
\end{tabular}

Table 10 explains the clear picture of EASc in pretest and posttest conditions. In the pretest, the mean value of EKT is 14.059 with SD 11.97 while mean and SD for posttest condition is respectively 13.71 and 1.91 . The $r$ value and $t$ value is .091

Table 11: Showing the mean, SD, $r$ and $t$ value of EASd.

\begin{tabular}{|c|c|c|c|c|c|c|c|}
\hline \multicolumn{9}{|c|}{ Paired Samples Statistics } \\
\hline & & Mean & N & Std. Deviation & r & t & Significance \\
\hline Pair 1 & EASd-1 & 69.5765 & 85 & 6.54358 & .077 & 1.233 & NS \\
\hline & EASd-2 & 70.6941 & 85 & 5.75703 & & & \\
\hline
\end{tabular}

Table 11 depicts the clear picture of EASc in pretest and posttest conditions. In the pretest, the mean value of EKT is 69.5765 with SD 6.5435 while mean and SD for posttest condition is respectively 70.6941 and 5.7570 . The $r$ value and and 0.265 , which is not significant. It means that the SSC model does not make a significant difference. Hence, the effect was not significant. the SSC model makes a significant difference in environmental attitude of participants. This is because people started to think on this topic seriously. Hence, the SSC model worked almost $95 \%$ only in one setting. 


\section{Psychology and Behavioral Science International Journal}

Table 12: Showing the mean, SD, $r$ and $t$ value of EASe.

\begin{tabular}{|c|c|c|c|c|c|c|c|}
\hline \multicolumn{7}{|c|}{ Paired Samples Statistics } \\
\hline & & Mean & N & Std. Deviation & r & S Significance \\
\hline Pair 1 & EASe-1 & 14.6706 & 85 & 3.42396 & .093 & 1.410 & NS \\
\hline & EASe-2 & 15.2706 & 85 & 2.25931 & & & \\
\hline
\end{tabular}

Table 12 describes the clear picture of EASe in pretest and posttest conditions. In the pretest, the mean value of EKT is 14.6706 with SD 3.4239 while mean and SD for posttest condition is respectively 15.2706 and 2.2593. The $r$ value and t value is .093 and 1.410, which is not significant. It means that the SSC model does not make a significant difference. Hence, the effect was not significant.

Table 13: Showing the mean, SD, $r$ and $t$ value of EASf.

\begin{tabular}{|c|c|c|c|c|c|c|c|}
\hline \multicolumn{9}{|c|}{ Paired Samples Statistics } \\
\hline & & Mean & N & Std. Deviation & r & t & Significance \\
\hline Pair 1 & EASf-1 & 41.7059 & 85 & 4.33376 & .196 & 2.192 & 0.05 \\
\hline & EASf-2 & 42.9529 & 85 & 3.92460 & & & \\
\hline
\end{tabular}

Table 13 gives the clear idea the Environmental attitude in pretest and posttest conditions. In the pretest, the value of mean EASf is 41.71with SD4.33 while mean and SD for posttest condition is respectively 42.95 and 3.92.The $r$ value and t value is 0.196 and 2.192 respectively which is significant. It means that the SSC model makes a significant difference in environmental attitude of participants. This is because people started to think on this topic seriously. Hence, the SSC model worked almost $95 \%$ only in one setting.

\section{Conclusion}

Through the primary survey, we can conclude that students are not so active in solving the environmental problems. Our SSC model works out effectively in only a single setting with respect to the aspects like environmental attitude, ethics, etc. It didn't prove so effective for some factors. But by modifying it and with repeated hammering on youngster's mind, we can make them environment-friendly.

a) The SSC model did not make a significant change in environmental knowledge, some aspects in environmental attitude including air pollution.

b) The SSC model makes a significant change in environmental ethics, environmental pollution attitude.

\section{References}

1. Dinesh A Dadhania (2014) Environmental Psychology. Paradise Publishers, Jaipur, India.

2. Hummel CF, Effects of induced cognitive set in view air pollution science.

3. Baron RA, Bell PA (1975) Aggression and heat; Mediating effect of prior provocation and exposure to an aggressive model. J Pers Soc Psychol 31(5): 825-832.

\section{Your next submission with JuniperPublishers will reach you the below assets}

- Quality Editorial service

- Swift Peer Review

- Reprints availability

- E-prints Service

- Manuscript Podcast for convenient understanding

- Global attainment for your research

- Manuscript accessibility in different formats

( Pdf, E-pub, Full Text, Audio)

- Unceasing customer service

Track the below URL for one-step submission https://juniperpublishers.com/online-submission.php 